\title{
Preoperative sedentary behavior is neither a risk factor for perioperative neurocognitive disorders nor associated with an increase in peripheral inflammation, a prospective observational cohort study
}

Sarah Saxena ${ }^{1,2}$, Christopher Rodts' ${ }^{1}$, Vincent Nuyens ${ }^{3}$, Juliette Lazaron ${ }^{1}$, Victoria Sosnowski ${ }^{1}$, Franck Verdonk ${ }^{4}$, Laurence Seidel ${ }^{5}$, Adelin Albert ${ }^{5}$, Jean Boogaerts ${ }^{1}$, Veronique Kruys ${ }^{6}$, Mervyn Maze ${ }^{2}$ and Joseph Vamecq ${ }^{7 *}$ (i)

\begin{abstract}
Background: Surgical interventions result in a postoperative rise in circulating inflammatory cytokines and high molecular group box protein 1 (HMGB1). Herein, the impact of a sedentary lifestyle and other age-related factors on the development of perioperative neurocognitive disorders (PND) following non-cardiac surgical procedures was assessed in an older (55-75 years-old) surgical population.

Methods: Prior to surgery, patients were asked questions regarding their sedentary behavior and daily habits. They also passed the Mini Mental State Examination (MMSE) and their blood circulating interleukin 6 (IL-6) and HMGB1 levels were assayed by ELISA. IL-6 and HMGB1 measurements were repeated respectively 6 and $24 \mathrm{~h}$ after surgery. MMSE was re-evaluated 6 weeks and whenever possible 3 months after surgery.

Results: Thirty-eight patients were enrolled in the study from January until July 2019. The study identified selfsufficiency, multilinguism, and overall health score on the geriatric depression scale, as protectors against PND. No other demographic (age, sex), environmental (solitary/non-solitary housing, professional and physical activities, smoking, alcohol drinking), comorbidity (antipsychotic drug uptake, diabetic state) and type of surgery (orthopedic, general, genitourinary) influenced the development of PND. Although some factors (surgery type and age) influenced the surgery-induced rise in the circulating IL-6 levels, they did not impact HMGB1.

(Continued on next page)
\end{abstract}

\footnotetext{
* Correspondence: joseph.vameca@inserm.fr

${ }^{7}$ Inserm, CHU Lille, Univ Lille, Department of Biochemistry and Molecular Biology, Laboratory of Hormonology, Metabolism-Nutrition \& Oncology (HMNO), Center of Biology and Pathology (CBP) Pierre-Marie Degand, CHRU Lille, EA 7364 RADEME, University of North France, Lille, France

Full list of author information is available at the end of the article
}

(c) The Author(s). 2020 Open Access This article is licensed under a Creative Commons Attribution 4.0 International License, which permits use, sharing, adaptation, distribution and reproduction in any medium or format, as long as you give appropriate credit to the original author(s) and the source, provide a link to the Creative Commons licence, and indicate if changes were made. The images or other third party material in this article are included in the article's Creative Commons licence, unless indicated otherwise in a credit line to the material. If material is not included in the article's Creative Commons licence and your intended use is not permitted by statutory regulation or exceeds the permitted use, you will need to obtain permission directly from the copyright holder. To view a copy of this licence, visit http://creativecommons.org/licenses/by/4.0/ The Creative Commons Public Domain Dedication waiver (http://creativecommons.org/publicdomain/zero/1.0/) applies to the data made available in this article, unless otherwise stated in a credit line to the data. 
(Continued from previous page)

Conclusion: Inflammaging, reflected by the greater increment of surgery-induced IL-6 in patients with advanced age, was present. As trauma-induced release of HMGB1 was not similarly affected by age, we surmise that HMGB1, rather than circulating cytokines, is the key driver of the trauma-induced inflammatory cascade leading to PND.

Trial registration: Clinicaltrials.gov identifier: NCT03805685.

Keywords: Inflammation, Perioperative neurocognitive disorders, Cognition, Interleukin-6, High molecular group box 1

\section{Background}

Perioperative neurocognitive dysfunction (PND) was first described in $1887[1,2]$. PND remains an important often under-diagnosed, surgical complication that is associated with increased mortality, risk of leaving the labor market prematurely, and dependency on unemployment/disability payments [2, 3]. The etiology of PND is not fully clarified although the type of anesthetic [4], intra-operative physiological perturbations (especially, hypotension and hypoxemia) [5] and the depth of sedation/anesthesia [6] have been advocated and rejected as causally-related. Over the last decade, several studies have suggested that the trauma-induced inflammatory cascade is a key pathogenic mechanism for the development of PND [7-9].

During surgery under general anesthesia the high molecular group box protein 1 (HMGB1) is released into the circulation from traumatized tissues [7]. This damageassociated molecular pattern (DAMP) binds to pattern recognition receptors on circulating bone marrow-derived monocytes (BM-DMs), hence triggering the nuclear translocation of the transcription factor NF- $\mathrm{BB}$ which activates gene expression and release of pro-inflammatory cytokines including IL-6 and IL-1 $\beta$ [7]. The onset of this inflammatory state disrupts the blood brain barrier [8]. Within the brain parenchyma the chemokine MCP-1 (also referred to as CCL2) is upregulated and, by signaling through its receptor CCR2, attracts the BM-DMs [9]. The influx of BM-DMs activates the resident quiescent microglia. Together, BM-DMs and activated microglia release HMGB1, IL-6 and IL-1 $\beta$, thereby disrupting long-term potentiation and the synaptic plasticity involved in cognitive functions of learning and memory [10-12]. Inability to successfully resolve the inflammatory cascade promotes the development of PND [13-15].

Several risk factors have been reported for PND including middle and advanced age and metabolic syndrome when inflammation resolution is retarded [16-18]. As sedentary lifestyle has also been associated with poorlyresolved inflammation $[19,20]$, we aimed to investigate the impact of sedentary behavior of elderly surgical patient on inflammation (evaluated by circulating IL-6 and HMGB1 levels) and PND (evaluated by MMSE 6 weeks postoperatively).

\section{Methods}

\section{Patient enrollment and ethics}

This prospective, non-controlled, observational cohort study adhered to the Declaration of Helsinki and the STROBE checklist and was approved by the internal review board (ethical committee of the "Intercommunale de Santé Publique du Pays de Charleroi-OM008”). Written informed consent was obtained from each patient enrolled in the study. The trial was registered on clinicaltrials.gov (NCT03805685) (https://clinicaltrials.gov/ ct $2 /$ show $/$ NCT03805685? term $=$ NCT03805685\&draw $=$ $2 \&$ rank $=1$ ) and conducted at the University Hospital of Charleroi, Charleroi, Belgium between January and August 2019.

\section{Inclusion/exclusion criteria}

Inclusion criteria were surgical patients, of both sexes aged 55 to 75 years, scheduled for surgical interventions of 1-4h. Exclusion criteria were cardiac surgery and neurosurgery, patients who did not understand English, French or Dutch, and patients with visual/auditory impairments, chronic and acute infections, or inability to perform cognitive testing.

In practice, not excluded surgical types were categorized into general, genitourinary and orthopedic surgeries to individualize their possible influence on study endpoints. Overall, these inclusion/exclusion criteria were chosen to constitute a homogenous surgical patient population in which perioperative care could be standardized.

\section{Pre- and post-operative assessments}

Prior to surgery, patients had a baseline Mini-Mental Status Examination (MMSE) assessment by a trained assessor. Relevant patient demographic information, including smoking and alcohol consumption, was collected. Data from the large version of the International Physical Activity Questionnaire (IPAQ) and the Geriatric Depression Scale (GDS) were also recorded for each patient. A peripheral blood sample was drawn to evaluate circulating IL-6 and HMGB1 levels (analyzed by ELISA) and used as inflammatory and DAMP markers. Six hours postoperatively, a peripheral blood sample was drawn again as well as $24 \mathrm{~h}$ postoperatively to re-evaluate inflammatory and DAMP markers. Patient MMSE was re-assessed 6 weeks and whenever 
Table 1 Baseline characteristics of study patients $(n=38)$

Variable
Age (years)
Sex
BMl $\left(\mathrm{kg} / \mathrm{m}^{2}\right)(n=37)$

Education level

No. of languages known

6

Working

Marital status

Self-sufficient

Living environment

(No. of people)

Number of alcoholic

drinks/weeks

Smoking Status

$\begin{array}{lll} & \begin{array}{ll}\text { Past smoker } \\ \text { (Mean no. of years }\end{array} & 14(36.8) \\ & \begin{array}{l}\text { since quitting) } \\ \text { Current smoker }\end{array} & 9(23.7) \\ & \begin{array}{l}\text { (Mean no. of } \\ \text { Cigarettes/day) }\end{array} & 12.2 \pm 7.3 \\ & \text { General } & 12(31.6) \\ \text { Surgery } & \text { Genitourinary } & 15(39.5) \\ & \text { Orthopedic } & 11(28.9) \\ \text { No. of psychoactive drugs } & 0 & 32(84.2) \\ & 1 & 5(13.2) \\ \text { Type of psychoactive } & 2 & 1(2.6) \\ \text { drug }(n=6) & \text { Benzodiazepines } & 5(83.3) \\ \text { Type 2 diabetes } & \text { SSRl } & 1(16.7) \\ & \text { No } & 28(73.7) \\ & \text { Yes } & 10(26.3)\end{array}$

Table 1 Baseline characteristics of study patients $(n=38)$ (Continued)

\begin{tabular}{|c|c|c|}
\hline Variable & Category & $\begin{array}{l}\text { Mean } \pm \text { SD } \\
\text { Number (\%) }\end{array}$ \\
\hline IPAQ work-related (h/week) & & $0.26 \pm 0.92$ \\
\hline IPAQ transport-related (h/day) & & $0.63 \pm 0.76$ \\
\hline IPAQ household-related (h/day) & & $0.42 \pm 0.60$ \\
\hline IPAQ leisure time-related (h/day) & & $0.19 \pm 0.41$ \\
\hline IPAQ sitting time (h/day) & & $7.3 \pm 2.4$ \\
\hline Energy (METs-min) & & $239 \pm 242$ \\
\hline GDS $(0-30)$ & & $6.66 \pm 4.43$ \\
\hline MMSE (/30) & & $25.8 \pm 4.19$ \\
\hline IL-6 (pg/ml) $(n=31)$ & & $31.2 \pm 33.9$ \\
\hline HMGB1 $(p g / m l)(n=33)$ & & $38.9 \pm 85.6$ \\
\hline
\end{tabular}

possible 3 months after surgery by a trained assessor. The primary endpoint was defined as the change in MMSE score between baseline and 6 weeks post-surgery. The study particularly focused on the relationship between the 6-week change in MMSE and sedentary lifestyle as measured by the IPAQ recorded sitting time (h/day).

\section{Anesthesia management}

Standardized anesthetic management included ECG, pulse oximetry, non-invasive blood pressure (every three minutes) and neuromuscular blockade monitoring (utilizing the trainof-four ratio). General anesthesia was induced with intravenous sufentanil $\left(0.2 \mu \mathrm{g} \mathrm{kg}^{-1}\right)$, lidocaine $\left(1-1.5 \mathrm{mg} \mathrm{kg}^{-1}\right)$ and propofol (2-3 $\left.\mathrm{mg} \mathrm{kg}^{-1}\right)$. Rocuronium $\left(0.5-1 \mathrm{mg} \mathrm{kg}^{-1}\right)$ was administered to facilitate tracheal intubation. Additional 10$20 \mathrm{mg}$ boluses of I.V. rocuronium were administered when necessary. Anesthesia was then maintained with $0.5-2.5 \%$ sevoflurane in an $\mathrm{O}_{2}$-air mixture, the latter being titrated to maintain oxygen saturation (SpO2) to a value of $96 \%$ or higher via pulse oximetry. Phenylephrine was used to maintain mean arterial blood pressure within $20 \%$ of the preoperative value. Acetaminophen $(1000 \mathrm{mg})$ and diclofenac $(1$ $\mathrm{mg} \mathrm{kg}^{-1}$ ) were administered for analgesia in all patients. I.V. sugammadex $\left(4 \mathrm{mg} \mathrm{kg}^{-1}\right)$ was administered to reverse neuromuscular blockade. After extubation, patients were placed in the post-anesthesia care unit, before returning to the ward.

\section{Statistical analysis}

We hypothesize a relationship between sedentary lifestyle and PND in (pre-) elderly subjects undergoing surgery. A sample size calculation setting power at $80 \%$ and significance level at $5 \%$ showed that by enrolling at least 29 patients in the study, a correlation of $0.50(25 \%$ of explained variance) could be evidenced between 
IPAQ sitting time and a drop in MMSE 6 weeks after surgery using a two-sided Student $t$ test.

Results were summarized as mean and standard deviation (SD) for quantitative variables and as median and interquartile range (IQR) for skewed data. Frequency tables (number, percent) were used for categorical findings. Some variables were log-transformed (IL-6, HMGB1) or square root transformed (IPAQ items) to normalize their distribution and statistical analyses were done on the transformed data. The correlation coefficient was used to measure the association between two quantitative variables. Changes in MMSE scores between baseline and other time points $(6 \mathrm{w}$ and $3 \mathrm{~m})$ were assessed by the paired Student $t$ test, and similarly for IL- 6 and HMGB1 changes. To test the overall effect of baseline covariates on evolution of MMSE, IL-6 and HMGB1, data were also analyzed by linear mixed effect models. Time adjusted effects of covariates were then expressed as regression coefficients with standard error (SE); a positive (negative) coefficient would indicate an increasing (decreasing) impact of the covariate on the outcome. The statistical significance level was set at $5 \%(p<0.05)$. Calculations and graphs were done with SAS (version 9.4) and R (version 3.6.1).

\section{Results}

\section{Study conduct and patient baseline characteristics}

Thirty-eight patients were included in the study. Their baseline characteristics are described in Table 1. In particular, the median IPAQ sitting time was $7 \mathrm{~h} /$ day (IQR: 6-9 h/day). Of the 38 study patients, 6 (15.8\%) could not be evaluated after surgery.

\section{MMSE and patient characteristics}

As seen in Table 2, the mean MMSE score was $25.8 \pm 4.2$ at baseline and $23.6 \pm 4.86$ weeks after surgery. Based on the 32 patients who were seen at both visits, this corresponds to a significant decrease of $2.1 \pm 3.1$ points $(p=0.0006)$ or to an $8.2 \%$ drop from baseline. For the 19 patients whose MMSE was available 3 months after surgery, scores had gone up a little but tended to remain lower than baseline scores $(p=0.055)$. Regression analysis showed that the drop

Table 2 Time-related evolution of MMSE in study patients

\begin{tabular}{lllll}
\hline Variable & Time & $\begin{array}{l}\text { Number. } \\
\text { of patients }\end{array}$ & Mean \pm SD & Median (IQR) \\
\hline MMSE (0-30) & Baseline & 38 & $25.8 \pm 4.2$ & $27(23.0-30.0)$ \\
& 6 weeks & 32 & $23.6 \pm 4.8$ & $25(20.0-27.5)$ \\
& 3 months & 19 & $24.5 \pm 5.2$ & $26(21.0-29.0)$ \\
Drop MMSE & Baseline-6w & 32 & $2.1 \pm 3.1^{(\mathrm{a})}$ & $1.5(0.5-4.0)$ \\
& Baseline-3 m & 19 & $1.6 \pm 3.4^{(\mathrm{b})}$ & $1.0(0.0-3.0)$ \\
\hline
\end{tabular}

(a) $p=0.0006$ and ${ }^{\text {(b) }} p=0.055$ (both paired Student t-test)

MMSE Mini-mental state examination
Table 3 Effect of baseline parameters on the evolution of MMSE scores

\begin{tabular}{|c|c|c|}
\hline Variable & Coefficient (SE)* & $P$-value \\
\hline Age (years) & $-0.071(0.11)$ & 0.53 \\
\hline Gender (Male vs. Female) & $0.23(1.41)$ & 0.87 \\
\hline $\mathrm{BMI}\left(\mathrm{kg} / \mathrm{m}^{2}\right)$ & $-0.077(0.13)$ & 0.55 \\
\hline Education level $^{(\mathrm{a})}$ & $1.36(0.72)$ & 0.069 \\
\hline No. of languages known & $1.44(0.63)$ & 0.028 \\
\hline Working (Yes vs. No) & $2.95(1.64)$ & 0.080 \\
\hline \multicolumn{3}{|l|}{ Marital status } \\
\hline (Divorced vs Married) & $-0.080(1.75)$ & 0.96 \\
\hline (Widow vs. Married) & $0.65(2.13)$ & 0.76 \\
\hline Self-sufficient (Yes vs. No) & $6.44(2.31)$ & 0.0083 \\
\hline Living situation (No. of people) & $0.67(1.10)$ & 0.55 \\
\hline Number of alcoholic drinks/week ${ }^{(b)}$ & $0.48(0.53)$ & 0.37 \\
\hline \multicolumn{3}{|l|}{ Smoking Status } \\
\hline (Current vs. Never) & $-0.38(1.52)$ & 0.81 \\
\hline (Past vs. Never) & $-3.50(1.73)$ & 0.51 \\
\hline \multicolumn{3}{|l|}{ Surgery } \\
\hline (Orthopedic vs. General) & $1.52(1.76)$ & 0.39 \\
\hline (Genitourinary vs. General) & $-0.95(1.64)$ & 0.57 \\
\hline No. of psychoactive medications ${ }^{(b)}$ & $-0.91(1.75)$ & 0.61 \\
\hline Type 2 Diabetes (Yes vs. No) & $-2.82(1.50)$ & 0.068 \\
\hline IPAQ work-related (h/week) ${ }^{(\mathrm{b})}$ & $2.49(1.40)$ & 0.084 \\
\hline IPAQ transport-related $(\mathrm{h} / \text { day })^{(\mathrm{b})}$ & $0.78(1.45)$ & 0.59 \\
\hline IPAQ household-related (h/day) ${ }^{(\mathrm{b})}$ & $1.00(1.39)$ & 0.48 \\
\hline IPAQ leisure time-related $(\mathrm{h} / \mathrm{day})^{(\mathrm{b})}$ & $3.32(1.75)$ & 0.066 \\
\hline IPAQ sitting time $(h / \text { day })^{(b)}$ & $-1.75(1.53)$ & 0.26 \\
\hline Energy (METs-min) $)^{(b)}$ & $0.045(0.083)$ & 0.59 \\
\hline GDS & $-0.47(0.14)$ & 0.0015 \\
\hline MMSE baseline & $0.92(0.067)$ & $<0.0001$ \\
\hline IL-6 baseline $(\mathrm{pg} / \mathrm{ml})^{(\mathrm{c})}$ & $-0.31(0.46)$ & 0.50 \\
\hline IL-6 increase until $24 \mathrm{~h}$ (Yes vs. No) & $1.47(1.56)$ & 0.35 \\
\hline HMGB1 baseline $(\mathrm{pg} / \mathrm{ml})^{(\mathrm{c})}$ & $0.13(0.46)$ & 0.77 \\
\hline HMGB1 increase until $24 \mathrm{~h}$ (Yes vs. No) & $0.13(1.76)$ & 0.94 \\
\hline
\end{tabular}

*covariate regression coefficients are adjusted for time; a positive (negative) coefficient is associated with an increasing (lowering) impact of parameter on MMSE scores over time

(a) treated as an ordinal variable

(b) square root transform applied to normalize the distribution

(c) log-transform applied to normalize the distribution

$B M I$ Body mass index, SE Standard error, MMSE Mini-mental state examination, IPAQ International Physical Activity questionnaire (long version), IL Interleukin, HMGB1 High molecular group box protein 1, GDS Geriatric depression score

in MMSE score after 6 weeks (primary endpoint) was not related to daily sitting time (correlation coefficient $0.11, p=0.55)$. Linear mixed model analysis on timerelated MMSE data (Table 3) confirmed this finding (regression coefficient $\pm \mathrm{SE}:-1.75 \pm 1.53, p=0.26$ ). It also evidenced that knowledge of several languages 


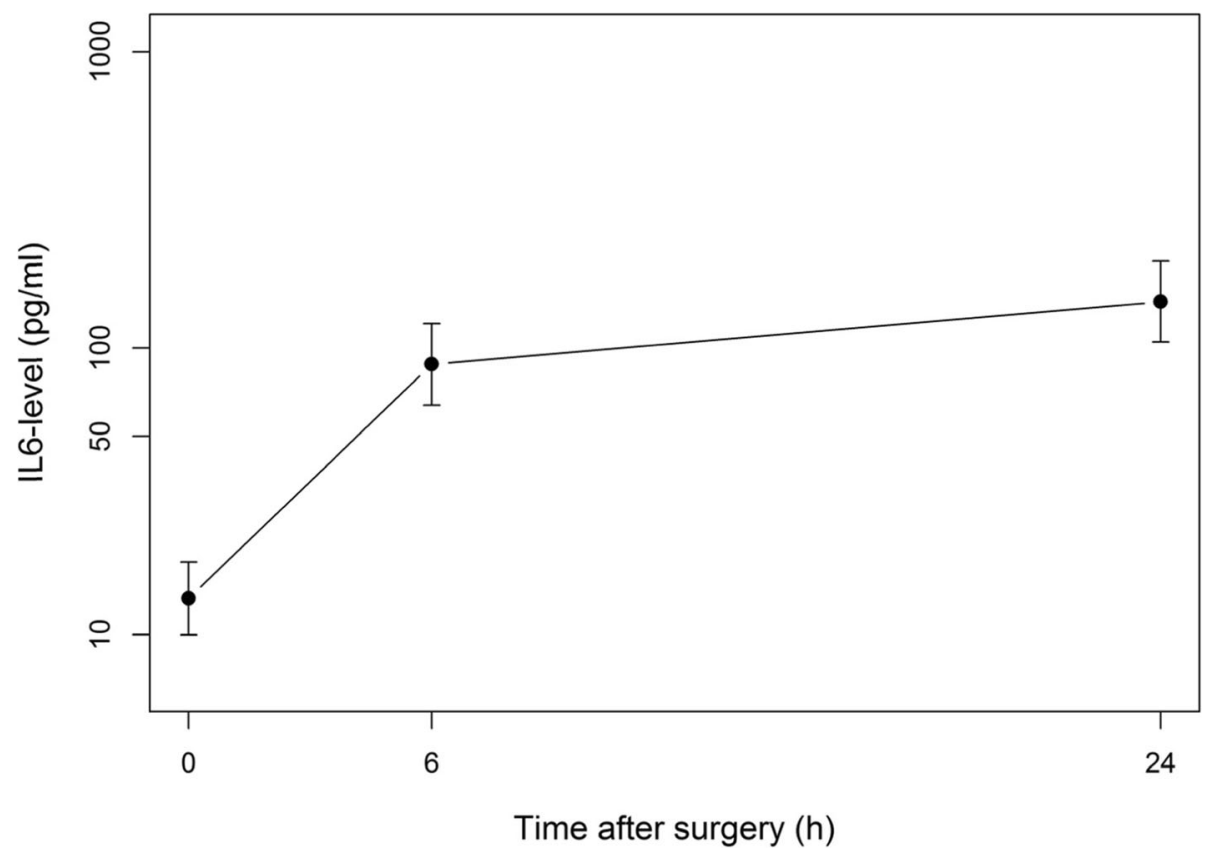

Fig. 1 Evolution of IL-6 (pg/ml) levels after surgery

$(p=0.028)$, being self-sufficient $(p=0.0083)$ and good pre-operative MMSE score $(p<0.0001)$ were associated with overall greater postoperative MMSE scores. By contrast, high baseline GDS scores were indicative of lower MMSE scores $(p=0.0015)$. Of note, a positive tendency was found for education level $(p=0.069)$, active working status $(p=0.080)$, number of hours of work per week $(p=0.084)$ and number of hours of leisure time per day $(p=0.066)$; type 2 diabetes tended to act as worsening of MMSE scores $(p=0.068)$. All other covariates turned out to have no real effect on postoperative MMSE scores, in particular IL-6 and HMGB1 baseline levels or their respective increase up to $24 \mathrm{~h}$ post-operatively.

\section{Inflammatory markers}

The distribution of IL-6 was highly skewed so data were log-transformed. The evolution of IL- 6 is displayed graphically in Fig. 1. The median (IQR) IL-6 level rose from $23.5(2.9-42) \mathrm{pg} / \mathrm{ml}$ at baseline to $138(46.3-247)$ $\mathrm{pg} / \mathrm{ml} 6 \mathrm{~h}$ after surgery $(p<0.0001)$. After $24 \mathrm{~h}$, levels were still higher than those at baseline with a median level of $193(86.8-528) \mathrm{pg} / \mathrm{ml}(p<0.0001)$. Linear mixed model analysis applied to assess the effect of each covariate on IL-6 time-related levels (Table 4 ) showed that age $(p=0.0044)$ and baseline IL-6 value $(p<0.0001)$ impacted positively post-operative IL-6 levels. By contrast, the number of psychoactive drugs taken preoperatively $(p=0.041)$ and the number of hours of work per week $(p=0.024)$ were associated with lower IL-6 levels after surgery. No other covariate was found to be of interest.
HMGB1 levels were also log-transformed. Their evolution within $24 \mathrm{~h}$ after surgery is depicted in Fig. 2. The median (IQR) HMGB1 level increased from 8.53 (4.627.2) $\mathrm{pg} / \mathrm{ml}$ at baseline to $19.9(12.0-33.2) \mathrm{pg} / \mathrm{ml} 6 \mathrm{~h}$ after surgery $(p=0.0075)$. Until $24 \mathrm{~h}, \mathrm{HMGB} 1$ levels continued to increase to reach a median level of 48.2 (24.475.6) $\mathrm{pg} / \mathrm{ml}$. When analyzing the relationship between each baseline covariate and post-operatives HMGB1 levels (Table 4), no association was found statistically significant, except for baseline HMGB1 levels $(p<$ 0.0001 ), indicating that patients with higher level before surgery mostly kept high levels after surgery.

\section{Discussion}

\section{Summary of findings}

The present study indicates that at least $75 \%$ of noncardiac surgical patients experienced a decrease in MMSE levels 6 weeks postoperatively with a highly significant mean drop of $2.1 \pm 3.1$ points $(p=0.0006)$. It also showed that a postoperative increase in IL-6 and HMGB1 levels was observed in all patients. Sedentary behavior expressed by the sitting time (h/day) is neither a risk factor for PND nor for postoperative peripheral inflammation and DAMP. In contrast to environmental factors, constitutive factors influenced MMSE scores and hence PND. Thus, patients who were self-sufficient and scored lower on the GDS had higher MMSE scores. Similarly, patients speaking multiple languages had better MMSE scores. Postoperative rise in IL-6 was influenced by age, number of psychoactive drugs taken by 
Table 4 Effect of baseline parameters on the time evolution of IL-6 and HMGB1 levels

\begin{tabular}{|c|c|c|c|c|}
\hline Variable & Coefficient (SE) on IL-6* & $P$-value & $\begin{array}{l}\text { Coefficient (SE) } \\
\text { on HMGB1* }\end{array}$ & $P$-value \\
\hline Age (years) & $0.13(0.041)$ & 0.0044 & $0.026(0.033)$ & 0.45 \\
\hline Gender (Male vs. Female) & $0.75(0.54)$ & 0.18 & $0.30(0.41)$ & 0.47 \\
\hline $\mathrm{BMI}\left(\mathrm{kg} / \mathrm{m}^{2}\right)$ & $0.027(0.049)$ & 0.59 & $-0.060(0.033)$ & 0.079 \\
\hline Education level $^{(a)}$ & $-0.27(0.29)$ & 0.35 & $-0.37(0.21)$ & 0.086 \\
\hline No. of languages known & $-0.027(0.25)$ & 0.95 & $0.24(0.19)$ & 0.21 \\
\hline Working (Yes vs. No) & $-0.79(0.63)$ & 0.23 & $0.15(0.50)$ & 0.77 \\
\hline \multicolumn{5}{|l|}{ Marital status } \\
\hline (Divorced vs Married) & $0.19(0.63)$ & 0.77 & $-0.25(0.48)$ & 0.60 \\
\hline (Widow vs. Married) & $-0.85(0.95)$ & 0.38 & $-0.45(0.64)$ & 0.49 \\
\hline Self-sufficient (Yes vs. No) & $-0.53(1.10)$ & 0.63 & $-0.22(0.73)$ & 0.77 \\
\hline Living situation (No. of people) & $0.038(0.42)$ & 0.93 & $0.33(0.31)$ & 0.29 \\
\hline No. of alcoholic drinks/week ${ }^{(b)}$ & $-0.078(0.22)$ & 0.72 & $-0.024(0.17)$ & 0.89 \\
\hline \multicolumn{5}{|l|}{ Smoking Status } \\
\hline (Current vs. Never) & $-0.45(0.63)$ & 0.48 & $0.55(0.45)$ & 0.23 \\
\hline (Past vs. Never) & $-0.73(0.71)$ & 0.31 & $0.79(0.53)$ & 0.15 \\
\hline \multicolumn{5}{|l|}{ Surgery } \\
\hline (Orthopedic vs. General) & $0.19(0.67)$ & 0.78 & $-0.39(0.49)$ & 0.44 \\
\hline (Genitourinary vs. General) & $-0.80(0.66)$ & 0.23 & $-0.90(0.48)$ & 0.073 \\
\hline No. of psychoactive medications ${ }^{(b)}$ & $-1.25(0.59)$ & 0.041 & $-0.40(0.47)$ & 0.40 \\
\hline Type 2 Diabetes (Yes vs. No) & $0.79(0.64)$ & 0.22 & $0.53(0.45)$ & 0.25 \\
\hline IPAQ work-related (h/week) ${ }^{(\mathrm{b})}$ & $-1.55(0.65)$ & 0.024 & $0.064(0.55)$ & 0.91 \\
\hline IPAQ transport-related $(\mathrm{h} / \text { day })^{(\mathrm{b})}$ & $-0.36(0.63)$ & 0.57 & $-0.41(0.44)$ & 0.36 \\
\hline IPAQ household-related $(\mathrm{h} / \text { day })^{(\mathrm{b})}$ & $-0.30(0.53)$ & 0.57 & $-0.65(0.38)$ & 0.092 \\
\hline IPAQ leisure time-related (h/day) ${ }^{(b)}$ & $-0.86(0.66)$ & 0.21 & $-0.093(0.51)$ & 0.86 \\
\hline IPAQ sitting time $(h / \text { day })^{(b)}$ & $0.058(0.62)$ & 0.93 & $-0.40(0.43)$ & 0.36 \\
\hline Energy (METs-min) $)^{(b)}$ & $-0.012(0.032)$ & 0.71 & $0.0030(0.023)$ & 0.90 \\
\hline GDS & $0.039(0.062)$ & 0.54 & $-0.009(0.045)$ & 0.84 \\
\hline MMSE baseline & $0.029(0.074)$ & 0.70 & $0.038(0.051)$ & 0.46 \\
\hline IL-6 baseline $(\mathrm{pg} / \mathrm{ml})^{(\mathrm{c})}$ & $0.86(0.084)$ & $<0.0001$ & $0.059(0.14)$ & 0.69 \\
\hline HMGB1 baseline $(\mathrm{pg} / \mathrm{ml})^{(\mathrm{c})}$ & $0.097(0.18)$ & 0.59 & $0.68(0.065)$ & $<0.0001$ \\
\hline
\end{tabular}

${ }^{*}$ covariate regression coefficients are adjusted for time; a positive (negative) coefficient is associated with an increasing (lowering) impact of parameter on IL- 6 or HMBD1 levels over time

(a) treated as an ordinal variable

(b) square root transform applied to normalize the distribution

(c) log-transform applied to normalize the distribution

$B M I$ Body mass index, SE Standard error, MMSE Mini-mental state examination, IPAQ International Physical Activity questionnaire, IL Interleukin, HMGB1 High molecular group box protein 1, METs Metabolic equivalents, GDS Geriatric depression scale

the patient and type of surgery. IL-6 levels were lower in patients with higher work-related IPAQ scores. Traumainduced HMGB1 was not influenced by demographic or environmental characteristics.

\section{Modifiable risk factors}

Lifestyle behavior has been advanced as a modifiable risk factor in the prevention of PND development [15]. Regarding baseline covariates, sedentary behavior is neither a risk factor for PND nor is it associated with an increase in peripheral inflammation in the elderly surgical patient. This finding contrasts with an earlier preclinical study which demonstrated that postoperative cognitive decline was higher in low capacity runner rats; preoperative exercise reversed the vulnerability for cognitive decline [12]. Similarly, a clinical study by Hudetz et al. demonstrated that patients with metabolic syndrome experienced reductions in tests of verbal memory and 


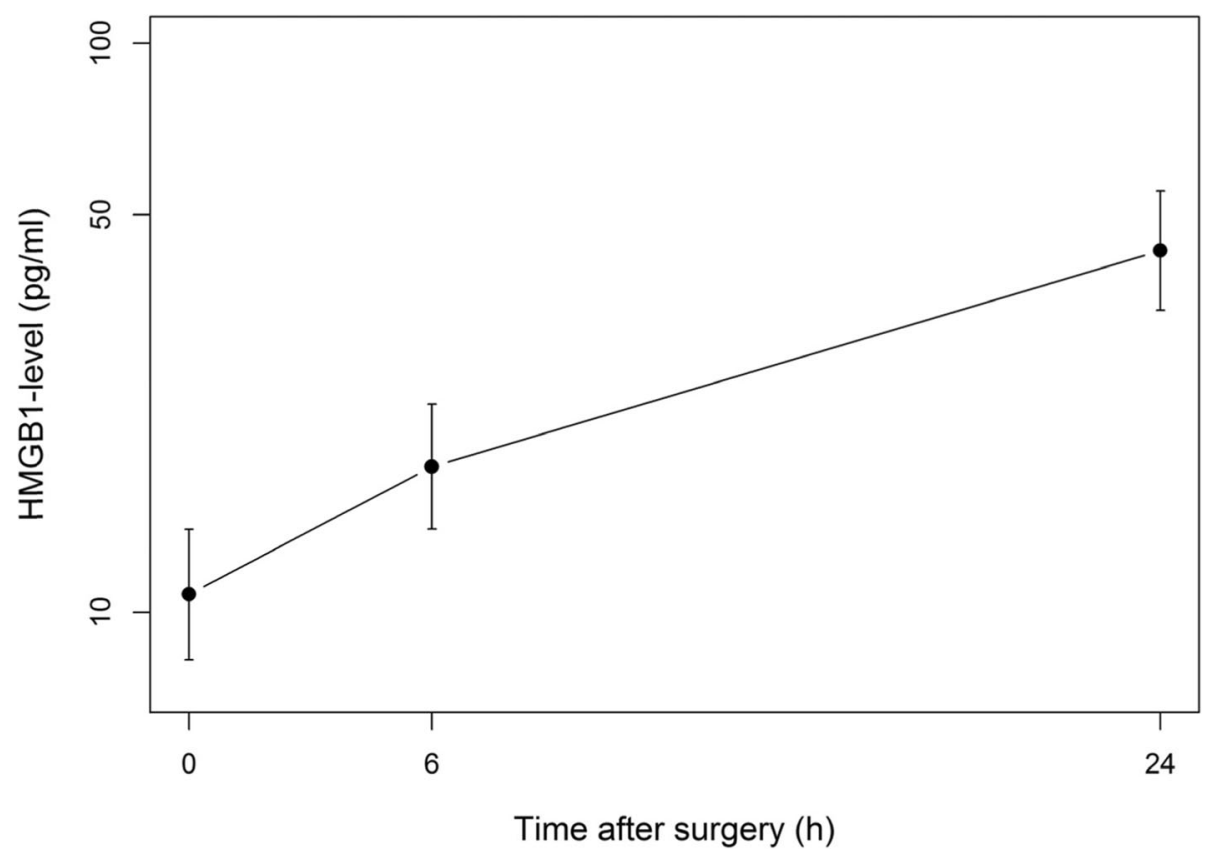

Fig. 2 Evolution of HMGB1 (pg/ml) levels after surgery

executive function and overall cognitive performance after surgery [17]. While sedentary behavior contributes to metabolic syndrome, the patients in our study did not necessarily suffer from this syndrome. This could perhaps explain the different results observed between this study and previous clinical and preclinical studies [12, 16-18].

\section{Constitutional risk factors: Inflammaging}

Aging is associated with immune dysregulation, of which the most evident characteristics are higher circulating levels of pro-inflammatory cytokines. Inflammaging is thought to contribute to many of the diseases of the elderly, such as infections, autoimmune disorders, and chronic inflammatory diseases $[21,22]$. A study by Cohen et al. showed the correlation between serum IL-6 levels and age [23]. Similarly, in this study, postoperative IL-6 increase was also influenced by age. Age ( $>60$ years old) has been suggested to be a risk factor for the development of PND [5, 17]; several studies confirm this association [24, 25].

\section{Surgery-associated HMGB1 release}

Surgery is associated with an increase in HMGB1, a well-known DAMP, in preclinical and clinical studies [26-28]. Similarly, in our study, HMGB1 levels increased postoperatively, regardless of age. Age-related inflammation, measured by baseline IL- 6 , did not correlate with these HMGB1 levels $(p=0.69)$. Preclinical studies have shown that disabling HMGB1 leads to lowering systemic and hippocampal inflammatory responses to surgery and prevents the development of PND $[7,29]$. This study demonstrates that while IL-6 levels were influenced by environmental and constitutive factors, this was not the case for the traumainduced release of HMGB1.

\section{Limitations}

This study both has and reveals some limitations. Firstly, at present, a consensus for neuropsychological testing tools to diagnose PND does not exist. MMSE, the cognitive testing tool used in this study, is widely accepted and used in clinical studies examining the incidence of PND because of its familiarity and ease of administration. However, it may be criticized as a cognitive diagnostic tool as it lacks the sensitivity and specificity to detect subtle cognitive impairment and it is limited by both floor and ceiling effects [30, 31]. Ideally, until a consensus is reached regarding the exact testing methods, a battery of cognitive tests should be used to diagnose PND. Nonetheless, in the present study, MMSE variations under constitutive and environmental factors have provided emerging clues for future studies.

Secondly, though exercise and sedentary behaviour are opposite sides of the same coin (degree of motor activity), they should be considered as two distinct entities. Previous work showed that, in a preclinical setting, the active introduction of exercise was 
associated with less post-operative cognitive dysfunction [32]. Our present study evaluates the impact of pre-existing sedentary behavior on perioperative cognitive dysfunction; however, as the effect of exercise on outcome was not measured we cannot assume that its effects will be the polar opposite of sedentary behavior.

Thirdly, in this study, peripheral cytokines were analyzed, examining only one part of the inflammatory cascade leading to PND. Large randomized controlled trials with peripheral serum and cerebrospinal fluid (CSF) samples are needed to further examine this inflammatory cascade. Lastly, the results of this study are based on the analysis of a limited sample of patients.

\section{Conclusion}

Surgery is associated with an increase in peripheral IL-6 and HMGB1 and with cognitive impairment 6 weeks postoperatively. Preoperative sedentary behavior is 'neither a risk factor for PND nor is it associated with an increase in peripheral inflammation, findings that correspond with pre-clinical data.

\section{Abbreviations \\ BM-DM: Bone marrow-derived monocytes; DAMP: Damage-associated molecular pattern; ELISA: Enzyme-linked immunosorbent assay; GDS: Geriatric Depression Scale; HMGB1: High molecular group box protein; IL-1 beta: Interleukin 1 beta; IL-6: Interleukin 6; IPAQ: International Physical Activity Questionnaire; IQR: Interquartile range; MMSE: Mini-mental state examination; PND: Perioperative neurocognitive disorders; SD: Standard deviation; SE: Standard error}

\section{Acknowledgements}

The authors thank the nursing staff of the University Hospital (CHU) of Charleroi, Belgium.

The authors would like to thank Laryssa Termini, Martine Vanstechelman and Fatiha Abidli for their logistic help.

\section{Authors' contributions}

All authors have read and approved the manuscript. SS: patient recruitment, data collection, writing up draft of the paper. CR: patient recruitment, data collection. VN: data analysis, study material preparation, study design. JL: patient recruitment, data collection. VS: patient recruitment, data collection. FV: data interpretation, revision of draft of paper. LS: data analysis and interpretation. AA: data analysis and interpretation. JB: study design, supervision, revision of draft of the paper. VK: study design, supervision. MM: data interpretation, revision of draft of the paper. JV: study design, supervision, data interpretation, draft and revision of paper.

\section{Funding}

Departmental funding

\section{Availability of data and materials}

The datasets used and/or analyzed during the current study are available from the corresponding author on reasonable request.

\section{Ethics approval and consent to participate}

This study was approved by the internal review board (ethical committee of the "Intercommunale de Santé Publique du Pays de Charleroi-OM008") and was registered on clinicaltrials.gov (NCT03805685) prior to patient enrolment. Written informed consent was obtained from each patient enrolled in the study.
Consent for publication

Not applicable.

\section{Competing interests}

The authors declare that they have no competing interests.

\section{Author details}

${ }^{1}$ Department of Anesthesia, University Hospital Center (CHU de Charleroi), Charleroi, Belgium. ${ }^{2}$ Department of Anesthesia and Perioperative Care, Center for Cerebrovascular Research, UCSF, San Francisco, CA, USA. ${ }^{3}$ Laboratory of Experimental Medicine (ULB unit 222), University Hospital Center (CHU de Charleroi), Charleroi, Belgium. ${ }^{4}$ Department of Anesthesiology, Perioperative and Pain Medicine, Stanford University School of Medicine, Stanford, CA, USA. ${ }^{5}$ Department of Biostatistics, University Hospital of Liège, Liège, Belgium. ${ }^{6}$ Laboratory of Molecular Biology of the Gene, Department of Molecular Biology, ULB Immunology Research Center (UIRC), Free University of Brussels (ULB), Gosselies, Belgium. ${ }^{7}$ Inserm, CHU Lille, Univ Lille, Department of Biochemistry and Molecular Biology, Laboratory of Hormonology, Metabolism-Nutrition \& Oncology (HMNO), Center of Biology and Pathology (CBP) Pierre-Marie Degand, CHRU Lille, EA 7364 RADEME, University of North France, Lille, France.

Received: 4 August 2020 Accepted: 5 November 2020

Published online: 14 November 2020

\section{References}

1. Savage $\mathrm{GH}$. Insanity following the use of anaesthetics in operations. BMJ. 1887;3:1199-200.

2. Evered L, Silbert B, Knopman DS, Scott DA, DeKosky ST, Rasmussen LS, et al. Recommendations for the nomenclature of cognitive change associated with Anaesthesia and Surgery-2018. Anesthesiology. 2018;129:872-9.

3. Steinmetz J, Christensen KB, Lund T, Lohse N, Rasmussen LS, ISPOCS group. Long-term consequences of postoperative cognitive dysfunction. Anesthesiology. 2009;110:548-55.

4. Patel V, Champaneria R, Dretzke J, Yeung J. Effect of regional versus general anaesthesia on postoperative delirium in elderly patients undergoing surgery for hip fracture: a systematic review. BMJ Open. 2018;8:e020757.

5. Moller JT, Cluitmans P, Rasmussen LS, Houx P, Rasmussen H, Rabbitt P, et al. Long-term postoperative cognitive dysfunction in the elderly ISPOCD1 study. ISPOCD investigators. International Study of Post-Operative Cognitive Dysfunction. Lancet. 1998;351:857-61.

6. Sieber FE, Neufeld KJ, Gottscalk A, Bigelow GE, Oh ES, Rosenberg PB, et al. Effect of depth of sedation in older patients undergoing hip fracture repair on postoperative delirium: the STRIDE randomized clinical trial. JAMA Surg. 2018;153:987-95.

7. Vacas S, Degos V, Tracey KJ, Maze M. High-mobility group box 1 protein initiates postoperative cognitive decline by engaging bone marrow-derived macrophages. Anesthesiology. 2014;120:1160-7.

8. Terrando N, Eriksson LI, Ryu JK, Yang T, Monaco C, Feldmann M, et al. Resolving postoperative neuroinflammation and cognitive decline. Ann Neurol. 2011;70:986-95.

9. Feng X, Valdearcos M, Uchida Y, Lutrin D, Maze M, Koliwad SK. Microglia mediate postoperative hippocampal inflammation and cognitive decline in mice. JCI Insight. 2017;2:e91229.

10. Cibelli M, Fidalgo AR, Terrando N, Monaco C, Feldmann M, Takata M, et al. Role of interleukin-1 beta in postoperative cognitive dysfunction. Ann Neur. 2010;68:360-8.

11. Hu J, Feng $X$, Valdearcos $M$, Lutrin D, Uchida $Y$, Koliwad SK, et al. Interleukin6 is both necessary and sufficient to produce perioperative neurocognitive disorder in mice. Br J Anaesth. 2018;120:537-45.

12. Feng $X$, Degos $V$, Koch LG, Britton $S L$, Zhu $Y$, Vacas $S$, et al. Surgery results in exaggerated and persistent cognitive decline in a rat model of the metabolic syndrome. Anesthesiology. 2013;118:1098-105.

13. Terrando N, Gomez-Galan M, Yang T, Carlstrom M, Gustavsson D, Harding $\mathrm{RE}$, et al. Aspirin-triggered Resolvin D1 prevents surgery-induced cognitive decline. FASEBJ. 2013;27:3564-71.

14. Yang T, Xu G, Newton PT, Chagin AS, Mkrtchian S, Carlstrom M, et al. Maresin 1 attenuates Neuroinflammation in a mouse model of perioperative neurocognitive disorders. BJA. 2019;122:350-60. 
15. Saxena S, Lai IK, Li R, Maze M. Neuroinflammation is a putative target for the prevention and treatment of perioperative neurocognitive disorders. $\mathrm{Br}$ Med Bull. 2019;130:125-35.

16. Monk TG, Weldon BC, Garvan CW, Dede DE, Van der Aa MT, Heilman KM, et al. Predictors of cognitive dysfunction after major noncardiac surgery. Anesthesiology. 2008;108:18-30.

17. Hudetz JA, Patterson KM, Amole O, Riley AV, Pagel PS. Postoperative cognitive dysfunction after noncardiac surgery: effects of metabolic syndrome. J Anesth. 2011;25:337-44.

18. Jones RN, Fong TG, Metzger E, Tulebaev S, Yang FM, Alsop DC, et al. Aging, brain disease and reserve: implications for delirium. Am J Geriatr Psychiatry. 2010;18:117-27.

19. Yates T, Khunti K, Wilmot EG, Brady E, Webb D, Srinivasan B, et al. Selfreported sitting time and markers of inflammation, insulin resistance, and adiposity. Am J Prev Med. 2012;42:1-7.

20. Alves BC, Silva TR, Spritzer PM. Sedentary lifestyle and high-carbohydrate intake are associated with low-grade chronic inflammation in post-menopause: a cross-sectional study. Rev Bras Ginecol Obstet. 2016;38:317-24.

21. Ferrucci L, Semba RD, Guralnik JM, Ershler WB, Bandinelli S, Patel KV, et al. Proinflammatory state, hepcidin, and anemia in older persons. Blood. 2010; 115:3810-6.

22. Fulop T, Larbi A, Dupuis G, Le Page A, Frost EH, Cohen AA, et al. Immunosenescence and Inflamm-aging as two sides of the same coin: friends or foes? Front Immunol. 2018:8:1960.

23. Cohen HJ, Pieper CF, Harris T, Rao KM, Currie MS. The association of plasma IL-6 levels with functional disability in community-dwelling elderly. J Gerontol A Biol Sci Med Sci. 1997;52:M201-8.

24. Luo A, Yan J, Tang X, Zhao Y, Zhou B, Li S. Postoperative cognitive dysfunction in the aged: the collision of neuroinflammaging with perioperative neuroinflammation. Inflammopharmacology. 2019;27:27-37.

25. Lin X, Chen Y, Zhang P, Chen G, Zhou Y, Yu X. The potential mechanism of postoperative cognitive dysfunction in older people. Exp Gerontol. 2020; 130:110791.

26. Degos V, Maze M, Vacas S, Hirsch J, Guo Y, Shen F, et al. Bone fracture exacerbates murine ischemic cerebral injury. Anesthesiology. 2013;118:1362-72.

27. Satoh M, Kotani K, Yamada S, Koinuma K, Horie H, Takeuchi M. Postoperative changes in high mobility group box 1 levels after colorectal cancer surgery. J Int Med Res. 2017;45:1651-7.

28. Lin GX, Wang T, Chen MH, Hu ZH, Ouyang W. Serum high-mobility group box 1 protein correlates with cognitive decline after gastrointestinal surgery. Acta Anaesthesiol Scand. 2014;58:668-74.

29. Terrando N, Yang T, Wang X, Fang J, Cao M, Andersson U, et al. Systemic HMGB1 neutralization prevents postoperative neurocognitive dysfunction in aged rats. Front Immunol. 2016;7:441.

30. Lonie JA, Tierney KM, Ebmeier KP. Screening for mild cognitive impairment: a systematic review. Int J Geriatr Psychiatry. 2009;24:902-15.

31. Mitchell A, Larner AJ. The mini-mental state examination (MMSE): update on its diagnostic accuracy and clinical utility for cognitive disorders. In: cognitive screening instruments. Cham: Springer International Publishing; 2017

32. Feng $X$, Uchida $Y$, Koch L, Britton S, Hu J, Lutrin D, Maze M. Exercise prevents enhanced postoperative Neuroinflammation and cognitive decline and rectifies the gut microbiome in a rat model of metabolic syndrome. Front Immunol. 2017;8:1768.

\section{Publisher's Note}

Springer Nature remains neutral with regard to jurisdictional claims in published maps and institutional affiliations.

Ready to submit your research? Choose BMC and benefit from:

- fast, convenient online submission

- thorough peer review by experienced researchers in your field

- rapid publication on acceptance

- support for research data, including large and complex data types

- gold Open Access which fosters wider collaboration and increased citations

- maximum visibility for your research: over $100 \mathrm{M}$ website views per year

At BMC, research is always in progress.

Learn more biomedcentral.com/submissions 